\title{
A Hydrophilic Channel is Involved in Oxidative Inactivation of a
}

[NiFeSe] Hydrogenase

\author{
Sónia Zacarias ${ }^{1}$, Adriana Temporão${ }^{1}$, Melisa del Barrio², Vincent Fourmond ${ }^{2}$, Christophe Léger², \\ Pedro M Matias ${ }^{1,3^{*}}$, Inês A C Pereira ${ }^{1 *}$
}

\begin{abstract}
${ }^{1}$ Instituto de Tecnologia Química e Biológica António Xavier, Universidade Nova de Lisboa, Av. da República, 2780157 Oeiras, Portugal

${ }^{2}$ Aix Marseille Univ., CNRS, Bioénergétique et Ingénierie des Protéines, 13402 Marseille CEDEX 09, France.

${ }_{3}^{3}$ iBET, Instituto de Biologia Experimental e Tecnológica, Apartado 12, 2780-901 Oeiras, Portugal
\end{abstract}

\section{Corresponding authors}

*matias@itqb.unl.pt

*ipereira@itqb.unl.pt
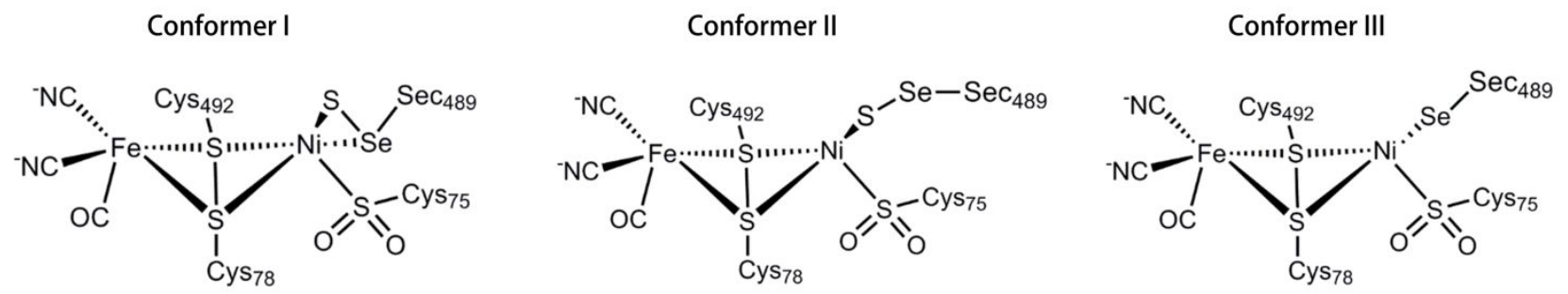

Figure S1. Active site conformations of the as-isolated $D$. vulgaris Hildenborough [NiFeSe] hydrogenase. In conformer I and II an exogenous sulfur is bound to $\mathrm{Ni}$, while in conformer III no exogenous sulfur is present and Se atom is bond directly to $\mathrm{Ni}$. The latter corresponds to the conformer found in the reduced form of the enzyme.

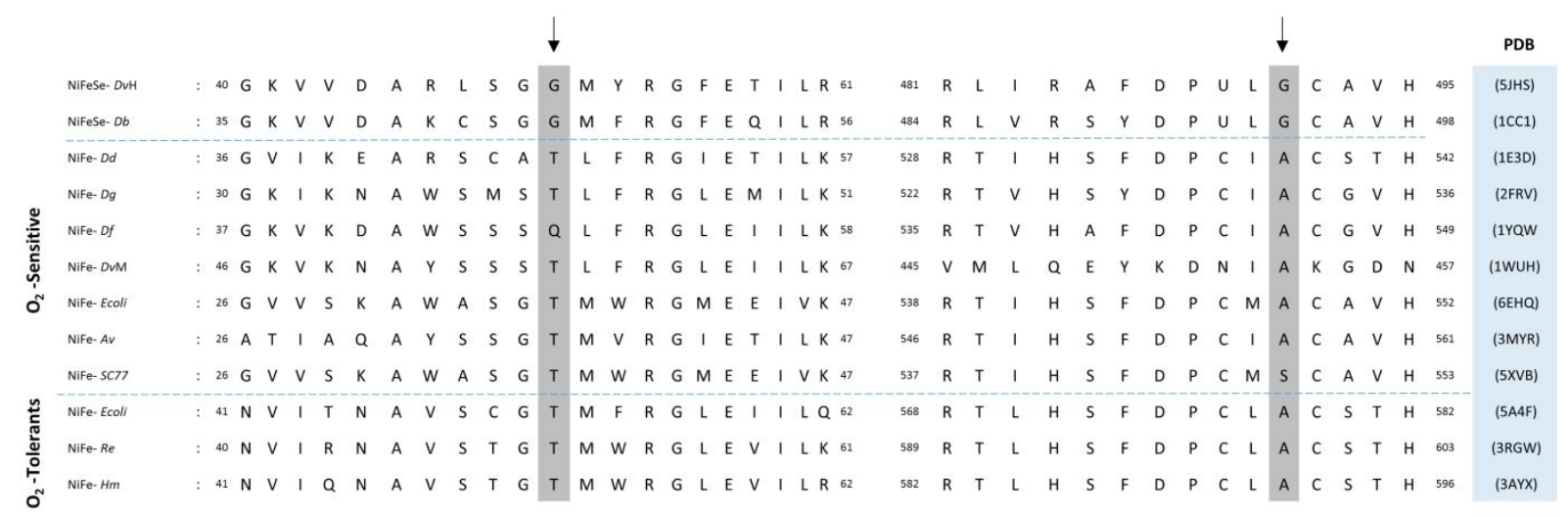

Figure S2. Structure-based sequence alignment of the large subunits of [NiFeSe] hydrogenases from $D$. vulgaris Hildenborough and $D$. baculatum with the standard $\mathrm{O}_{2}$-sensitive [NiFe] hydrogenases from $D$. desulfuricans ATCC 27774, D. gigas, D. fructosovorans, D. vulgaris Miyazaki, E. coli, Allochromatium vinosum and Citrobacter sp. S-77 with the [NiFe] $\mathrm{O}_{2}$-tolerant hydrogenases from E.coli Hyd-1, Ralstonia eutropha and 
Table S1. Data collection and processing statistics

G50T

G491A

G491S

\begin{tabular}{|c|c|c|c|}
\hline Data Collection & & & \\
\hline Beamline & ESRF ID29 & DLS 102 & ESRF ID30A-3 \\
\hline Detector & PILATUS3 6M & PILATUS 6M-F & PILATUS 6M \\
\hline Wavelength $(\hat{A})$ & 0.88560 & 0.97949 & 0.88560 \\
\hline Space Group & $C 2$ & $P 2_{1}$ & $C 2$ \\
\hline \multicolumn{4}{|l|}{ Unit cell parameters: } \\
\hline$a, b, c(\AA)$ & $106.18,62.68,110.30$ & $60.45,98.66,63.88$ & $105.41,63.59,110.70$ \\
\hline$\beta\left(^{\circ}\right)$ & 105.10 & 105.36 & 104.88 \\
\hline Data Processing ${ }^{a}$ & $\begin{array}{l}\text { AutoPROC / } \\
\text { STARANISO }\end{array}$ & $\begin{array}{l}\text { AutoPROC / } \\
\text { STARANISO }\end{array}$ & XDS/CCP4 \\
\hline $\begin{array}{l}\text { Resolution limits of ellipsoid fitted } \\
\text { to resolution cut-off surface }(A)\end{array}$ & $1.084,1.218,1.223$ & $1.36,1.56,1.54$ & - \\
\hline Resolution, spherical limits (Å) & $53.2-1.084(1.199-1.084)$ & $61.6-1.36(1.51-1.36)$ & $45.7-1.20(1.22-1.20)$ \\
\hline Nr. Observations & $972918(45622)$ & $329698(14355)$ & $1414791(50213)$ \\
\hline Unique reflections & $213931(10698)$ & $112189(5610)$ & $216144(9023)$ \\
\hline Multiplicity & $4.5(4.3)$ & $2.9(2.6)$ & $6.5(5.6)$ \\
\hline Completeness, spherical (\%) & $72.5(14.0)$ & $71.9(13.1)$ & $97.9(83.0)$ \\
\hline Completeness, ellipsoidal (\%) & $90.9(52.5)$ & $92.7(52.7)$ & - \\
\hline$R$-merge $(\%)^{b}$ & $11.1(87.1)$ & $6.2(58,9)$ & $10.1(133)$ \\
\hline R-p.i.m. $(\%)^{c}$ & $5.9(46.0)$ & $4.3(43.7)$ & $4.2(60.0)$ \\
\hline$</ / \sigma(I)>$ & $6.9(1.6)$ & $10.9(1.5)$ & $9.4(1.2)$ \\
\hline$C C^{1 / 2}$ & $0.992(0.575)$ & $0.996(0.613)$ & $0.999(0.509)$ \\
\hline Wilson $B\left(\AA^{2}\right)$ & 10.3 & 17.6 & 8.6 \\
\hline$Z^{d}$ & 1 & 1 & 1 \\
\hline Estimated $V_{M}{ }^{e}$ & 2.02 & 2.10 & 2.05 \\
\hline Estimated Solvent Content (\%) e & 39.2 & 41.4 & 40.0 \\
\hline
\end{tabular}

29 a Values in parentheses refer to the highest resolution shell; ${ }^{\mathrm{b}} \mathrm{R}-\mathrm{merge}=$ merging R-factor, $\left(\Sigma_{\mathrm{hkl}} \Sigma_{\mathrm{i}}\left|l_{\mathrm{i}}(\mathrm{hkl})-</(\mathrm{hkl})>\right|\right) /\left(\Sigma_{\mathrm{hkl}} \Sigma_{\mathrm{i}} /(\mathrm{hkl})\right)$

$30 \times 100 \%$; ${ }^{\mathrm{c}}$ R-p.i.m. = precision-independent R-factor, $\Sigma_{\text {hkl }}[1 /(\mathrm{N}-1)]^{1 / 2} \Sigma_{\mathrm{i}}\left|l_{\mathrm{i}}(\mathrm{hkl})-</(\mathrm{hkl})>\right| /\left(\Sigma_{\mathrm{hkl}} \Sigma_{\mathrm{i}} l_{\mathrm{i}}(\mathrm{hkl})\right) \times 100 \%{ }^{1}$ For each unique

31 Bragg reflection with indices (hkl), $l_{\mathrm{i}}$ is the $\mathrm{i}$-th observation of its intensity and $\mathrm{N}$ its multiplicity; ${ }^{\mathrm{d}} \mathrm{Nr}$. molecules in the asymmetric

32 unit; e According to Matthews $1968 .^{2}$

33

34 
Table S2. Refinement statistics

\begin{tabular}{|c|c|c|c|}
\hline Dataset & G50T & G491A & G491S \\
\hline Resolution limits $(\AA)^{a}$ & $53.2-1.10(1.11-1.10)$ & $49.3-1.36(1.37-1.36)$ & $45.71 .20(1.21-1.20)$ \\
\hline$R_{\text {work }} \mathrm{b}$ & $0.139(0.318)$ & $0.143(0.272)$ & $0.128(0.286)$ \\
\hline$R_{\text {free }}{ }^{\mathrm{c}}$ & $0.158(0.329)$ & $0.162(0.310)$ & $0.148(0.297)$ \\
\hline $\begin{array}{l}\text { ML coordinate error estimate } \\
(\AA) d\end{array}$ & 0.12 & 0.12 & 0.12 \\
\hline \multicolumn{4}{|l|}{$\begin{array}{l}\text { Model composition and } \\
\text { completeness }\end{array}$} \\
\hline Regions omitted e & -- & $1 \mathrm{~A}-6 \mathrm{~A}, 12 \mathrm{~B}-13 \mathrm{~B}$ & 12B \\
\hline Non-hydrogen protein atoms ${ }^{f}$ & 6099 & 5853 & 6018 \\
\hline Ligand/ion atoms & 45 & 45 & 45 \\
\hline Solvent molecules & 826 & 859 & 671 \\
\hline Glycerol molecules & 3 & 1 & 3 \\
\hline \multicolumn{4}{|l|}{ Mean $B$ values $\left(\AA^{2}\right)^{g}$} \\
\hline Protein & 13.6 & 18.8 & 14.0 \\
\hline Ligand/ion & 10.2 & 14.3 & 10.4 \\
\hline Solvent & 27.2 & 33.1 & 27.4 \\
\hline Glycerol & 35.4 & 23.9 & 34.8 \\
\hline \multicolumn{4}{|l|}{$\begin{array}{l}\text { Model r.m.s. deviations from } \\
\text { ideality }\end{array}$} \\
\hline Bond lengths $(\AA)$ & 0.008 & 0.010 & 0.008 \\
\hline Bond angles $\left(^{\circ}\right)$ & 1.328 & 1.314 & 1.273 \\
\hline Chiral centers $\left(\AA^{3}\right)$ & 0.088 & 0.089 & 0.089 \\
\hline Planar groups $(\AA)$ & 0.008 & 0.008 & 0.007 \\
\hline \multicolumn{4}{|l|}{ Model validation $\mathrm{h}$} \\
\hline \% Ramachandran outliers & 0.13 & 0.13 & 0.13 \\
\hline$\%$ Ramachandran favored & 97.6 & 97.6 & 98.0 \\
\hline$\%$ Rotamer outliers & 0.61 & 0.97 & 0.78 \\
\hline $\mathrm{C}^{\beta}$ outliers & 0 & 0 & 0 \\
\hline Clash score & 1.7 & 2.4 & 2.3 \\
\hline PDB Accession code & 6RTP & 6RU9 & 6RUC \\
\hline
\end{tabular}

a Values in parentheses refer to the highest resolution shell; ${ }^{b} R_{\text {work }}=\left(\Sigma_{\text {hkl }} \| F_{\text {obs }}(h k l)|-| F_{\text {calc }}(h k l)||\right) /\left(\Sigma_{\text {hkl }}\left|F_{\text {obs }}(h k l)\right|\right) \times 100$ $\%$; ${ }^{c} R_{\text {free }}$ is calculated as above from a random sample containing $5 \%$ of the total number of independent reflections measured; d Maximum-likelihood estimate by PHENIX; e HysA (large subunit) is chain B, HysB (small subunit is chain A); ${ }^{f}$ Including atoms in the alternate conformations of disordered groups of residues; ${ }^{g}$ Calculated from isotropic or equivalent isotropic B-values; ${ }^{h}$ Calculated with MolProbity. ${ }^{3}$ 


\begin{tabular}{|c|c|c|c|c|}
\hline & WT (5JHS) & G50T & G491A1 & G491S1 \\
\hline \multicolumn{5}{|l|}{ Ni atom ${ }^{a}$} \\
\hline Occupancy & $84 \%$ & $67 \%$ & $78 \%$ & $86 \%$ \\
\hline \multicolumn{5}{|l|}{ Sec489 } \\
\hline Conformer I & $52 \%$ & $46 \%$ & n.d. & $29 \%$ \\
\hline Conformer II & $20 \%$ & $20 \%$ & $23 \%$ & $18 \%$ \\
\hline Conformer III & $29 \%$ & $34 \%$ & $77 \%$ & $53 \%$ \\
\hline \multicolumn{5}{|l|}{ Cys75 } \\
\hline Not oxidized & - & $16 \%$ & $100 \%$ & $76 \%$ \\
\hline Sulfenate & $38 \%$ & $20 \%$ & - & $2 \%$ \\
\hline Sulfinate & $62 \%$ & $54 \%$ & - & $21 \%$ \\
\hline \multicolumn{5}{|l|}{$\mathrm{S}$ atom ${ }^{b}$} \\
\hline Occupancy & $96 \%$ & $81 \%$ & $71 \%$ & $83 \%$ \\
\hline \multicolumn{5}{|c|}{ Proximal Cluster ${ }^{c}$} \\
\hline$[4 \mathrm{Fe}-4 \mathrm{~S}]$ & $75 \%$ & $62 \%$ & $75 \%$ & $91 \%$ \\
\hline [4Fe-4S-2O] & $25 \%$ & $38 \%$ & $25 \%$ & $9 \%$ \\
\hline
\end{tabular}

53 a In all crystal structures, the $\mathrm{Ni}$ ion was refined with partial occupancy: $67 \%, 78 \%$ and $86 \%$ in G50T, G491A and G491S,

54 respectively, compared to $84 \%$ for the WT. The incomplete Ni occupancy probably results from a mismatch between the 55 rates of recombinant protein expression and the native nickel incorporation machinery; $4 \mathrm{~b}$ the sulfur species bound to the $56 \mathrm{Ni}$ and Se in conformers I and II was refined with occupation levels of $81 \%, 71 \%$ and $83 \%$, in G50T, G491A, and G491S 57 respectively, compared to $96 \%$ for the $\mathrm{WT} ;{ }^{\mathrm{c}}$ unlike the oxidation of Cys 75 to the sulfinate state, the partial oxidation of the 58 proximal iron-sulfur cluster to $\left[\mathrm{Fe}_{4} \mathrm{~S}_{4} \mathrm{O}_{2}\right]$ is reversible. ${ }^{5}$ In the previously reported WT structure the proximal iron-sulfur cluster was $25 \%$ oxidized $^{4}$ and, except for structure G491S where this oxidation level is only ca. $9 \%$, comparable values are observed for the G50T and G491A structures, $38 \%$ and $25 \%$ respectively.

61 
A

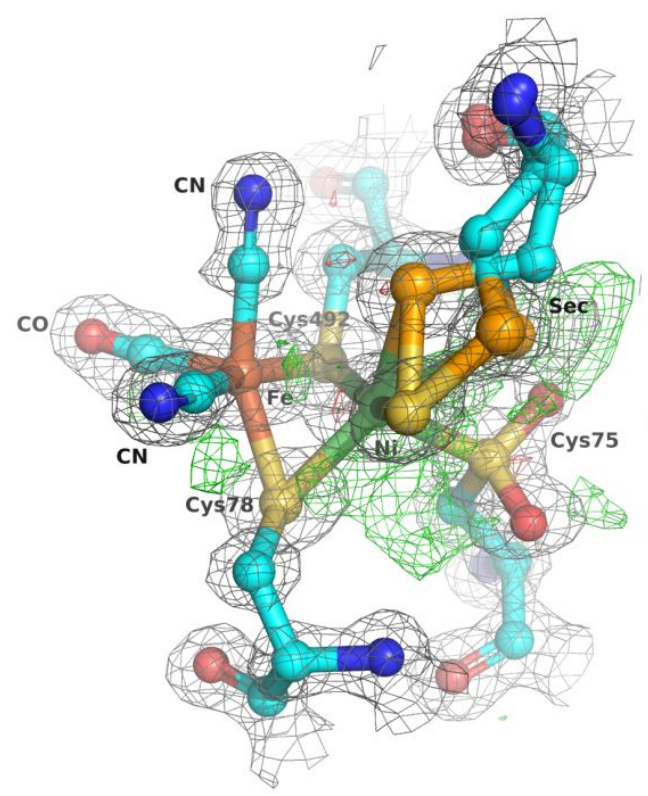

B

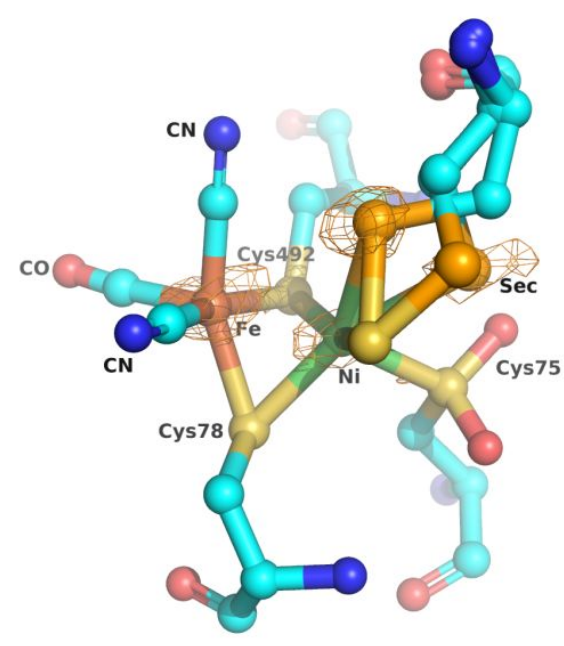

80

81

82

\section{G491S}

83

84

85

86

87

88

89

90
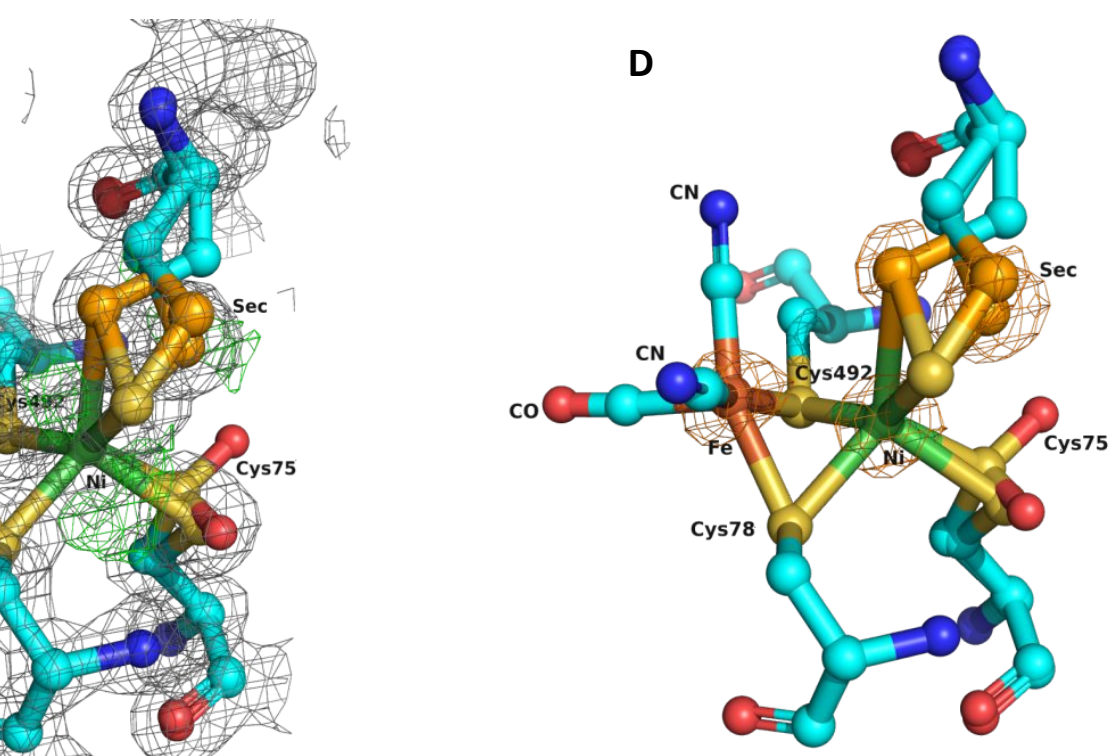

Figure S3. Active site of the aerobically purified and crystallized [NiFeSe] hydrogenase variants. (A, C) View of the refined structures of G50T (A) and G491S (C) with their corresponding $2\left|F_{o}\right|-\left|F_{c}\right|$ and $\left|F_{o}\right|-\left|F_{c}\right|$ maps, showing the additional Sec positions. The $2\left|F_{o}\right|-\left|F_{c}\right|$ map (gray mesh) is drawn at the 1.5 map r.m.s. level and the $\left|F_{o}\right|-\left|F_{c}\right|$ map is represented at the 3.5 (green mesh) and -3.5 (red mesh) map r.m.s. levels. (B, D) View of the final refined structure of G50T (B) and G491S (D) superimposed with the anomalous Fourier map (orange mesh) drawn at the 4.5 map r.m.s. level and calculated with phases from the partially refined structure represented in (a and c, respectively). The [NiFe] binuclear center and the sidechains of its protein ligands are represented in ball-and-stick and the protein chain is represented as a semitransparent cartoon. Atom colors are brown for iron, green for nickel, gold for sulfur, red for oxygen, light blue for carbon, blue for nitrogen and orange for selenium. Hydrogen atoms are omitted for clarity. 

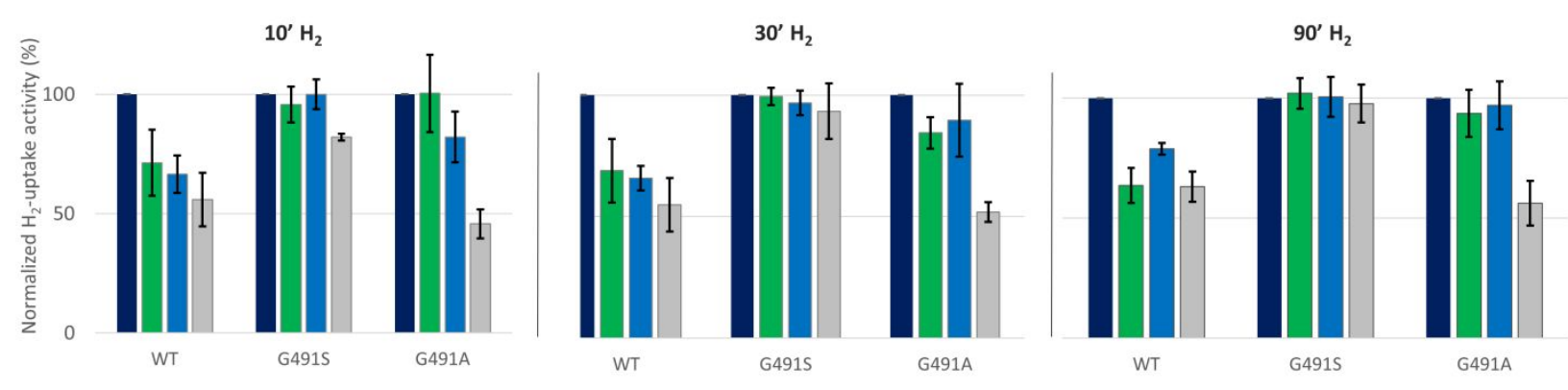

Figure S4. $\mathrm{H}_{2}$ uptake activity of WT and variants after 1 hour (green), 4 hours (blue) and overnight (grey) exposure to air, followed by 10,30 and 90 minutes reactivation under 0.5 atmosphere $\mathrm{H}_{2}$. The activities were normalized by the corresponding maximum activity of each protein (dark blue), reported in Table 1. The data correspond to the average of three individual experiments, each done in triplicate and the error bars correspond to the standard deviations.

Table S4. Channels predicted by CAVER in [NiFe] and [NiFeSe] hydrogenase structures

\begin{tabular}{|c|c|c|c|c|c|c|c|}
\hline Organism & PDB & $\begin{array}{l}\text { Starting } \\
\text { atom } 1 \\
\text { (a) }\end{array}$ & C1 & $\mathrm{C} 2$ & $\begin{array}{l}\text { Starting } \\
\text { atom } 2^{\text {a }} \\
\text { (a) }\end{array}$ & $\mathrm{C} 1$ & $\mathrm{C} 2$ \\
\hline$D v \mathrm{H}$ & 5jhs & $\mathrm{C} 75 \mathrm{~S} \gamma$ & Y & Y & - & - & - \\
\hline DvH G50T & This work & C75 S $\gamma$ & $\mathrm{N}$ & Y & - & - & - \\
\hline DvH G491A & This work & C75 S $\gamma$ & $\mathrm{N}$ & $\mathrm{N}$ & $\mathrm{A} 491 \mathrm{C} \beta$ & Y & Y \\
\hline$D v H$ G491S & This work & C75 Sy & $\mathrm{N}$ & $\mathrm{N}$ & S491 O $\gamma$ & Y & Y \\
\hline$D m b$ & $4 \mathrm{kn} 9$ & C70 Sy & $Y$ & $\mathrm{~N}$ & - & - & - \\
\hline DvMF & $4 u 9 h$ & $\mathrm{C} 81 \mathrm{~S} \gamma$ & $\mathrm{N}$ & $\mathrm{N}$ & $A 548 C \beta$ & $N$ & $N$ \\
\hline$D d$ & $1 e 3 d$ & C71 S $\gamma$ & $\mathrm{N}$ & $\mathrm{N}$ & $A 538 \mathrm{C} \beta$ & $N$ & $\mathrm{~N}$ \\
\hline$D g$ & $2 f r v$ & $\mathrm{C} 65 \mathrm{~S} \gamma$ & $\mathrm{N}$ & $\mathrm{N}$ & $A 532 C \beta$ & $\mathrm{N}^{\mathrm{b}}$ & $N^{b}$ \\
\hline$D f$ & 1yqw & C72 Sy & $\mathrm{N}$ & $\mathrm{N}$ & A545 C $\beta$ & $N$ & $N$ \\
\hline$E c$ & 6ehq & $\mathrm{C} 61 \mathrm{~S} \gamma$ & $\mathrm{N}$ & $\mathrm{N}$ & A548 C $\beta$ & $N$ & $N$ \\
\hline$A v$ & $3 m y r$ & C61 Sy & $N$ & $\mathrm{~N}$ & $A 557 C \beta$ & $N$ & $N$ \\
\hline Cs77 & $5 x v b$ & C61 Sy & $\mathrm{N}$ & $\mathrm{N}$ & S548 O $\gamma$ & Y & $N$ \\
\hline$E c$ & $5 a 4 f$ & C76 S $\gamma$ & $N$ & $\mathrm{~N}$ & $A 578 \mathrm{C} \beta$ & $\mathrm{N}$ & $N$ \\
\hline Re & $3 r g w$ & C75 S $\gamma$ & $N$ & $\mathrm{~N}$ & $A 599 \mathrm{C} \beta$ & $\mathrm{N}$ & $\mathrm{N}$ \\
\hline $\mathrm{Hm}$ & 3ayx & C76 Sy & $\mathrm{N}$ & $\mathrm{N}$ & $A 592 C \beta$ & $\mathrm{N}$ & $\mathrm{N}$ \\
\hline
\end{tabular}

112 a Both residues are in the large subunit. The second starting atom is explored in instances

113 where the first atom yields a negative result; ${ }^{b}$ a tunnel system with 5 branches appears in 114 this calculation, matching the hydrophobic tunnel system. 


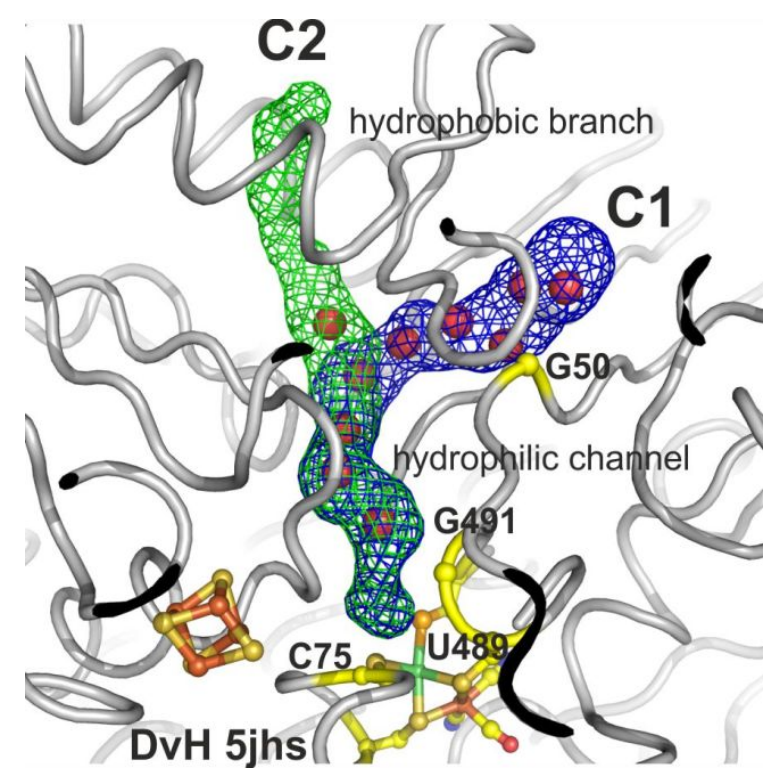

116 Figure S5. The hydrophilic channel (C1) and hydrophobic side-channel (C2) referenced in Table S4.

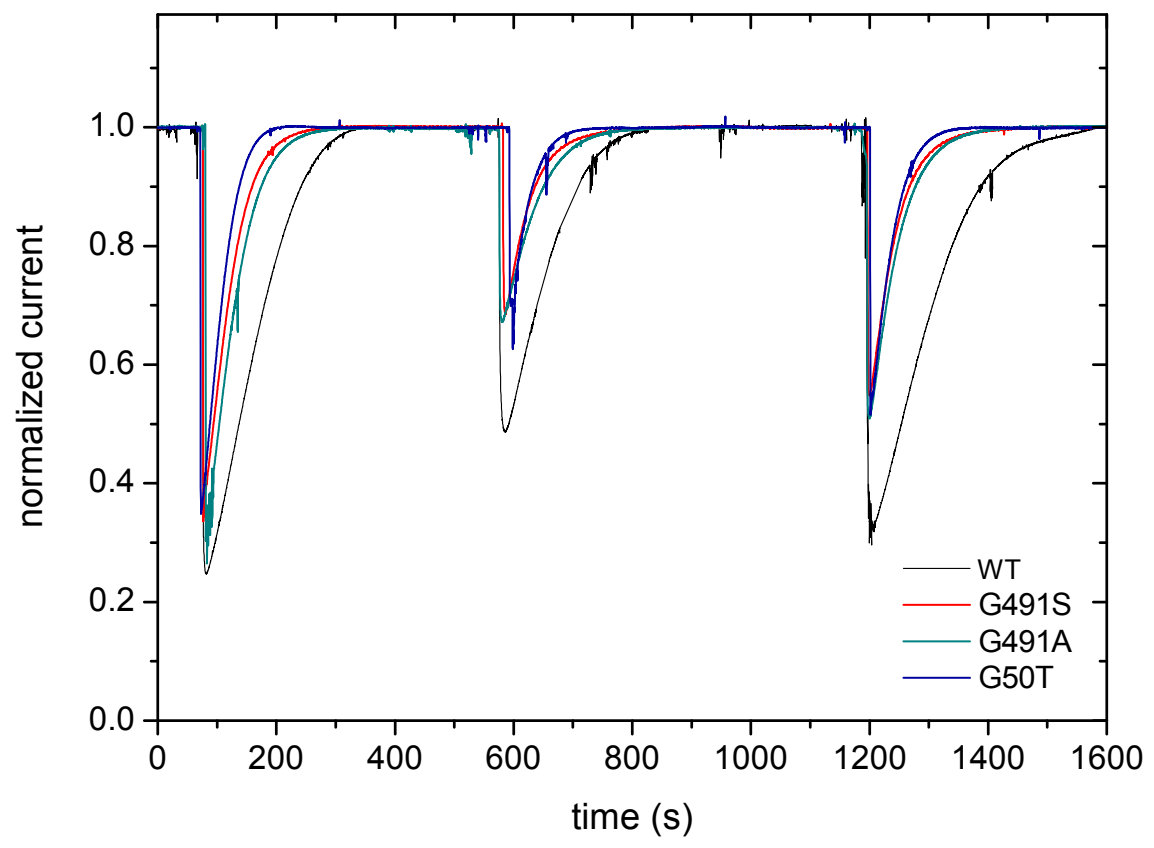

119 Figure S6. Effect of $\mathrm{CO}$ on the $\mathrm{H}_{2}$ oxidation current of WT [NiFeSe] hydrogenase and variants adsorbed onto 120 a graphite rotating electrode. Experimental conditions: [CO] = 4, 1, $2 \mu \mathrm{M}, \mathrm{E}=-0.060 \mathrm{~V}$ vs. SHE, 1 bar $\mathrm{H}_{2}, \mathrm{pH}$, $121 \mathrm{~T}=40^{\circ} \mathrm{C}$, electrode rotation rate $=3000 \mathrm{rpm}$. 
124 (1) Diederichs, K.; Karplus, P. A., Improved R-Factors for Diffraction Data Analysis in Macromolecular Crystallography. Nat. Struct. Biol. 1997, 4, 269-275.

126 (2) Matthews, B. W., Solvent Content of Protein Crystals. J. Mol. Biol. 1968, 33, 491-497.

127 (3) Chen, V. B.; Arendall, W. B.; Headd, J. J.; Keedy, D. A.; Immormino, R. M.; Kapral, G. J.; Murray, L. W.; Richardson, J. S.; Richardson, D. C.; Richardson, D. C., MolProbity: All-Atom Structure Validation for Macromolecular Crystallography. Acta Crystallogr. Sect. D Biol. Crystallogr. 2010, 66, 12-21.

130 (4) Marques, M.; Tapia, C.; Gutiérrez-Sanz, Ó.; Ramos, A. R.; Keller, K. L.; Wall, J. D.; De Lacey, A. L.; Matias, P. M.; Pereira, I. A. C., The Direct Role of Selenocysteine in [NiFeSe] Hydrogenase Maturation and Catalysis. Nat. Chem. Biol. 2017, 13, 554-550.

133 (5) Marques, M.; Coelho, R.; Pereira, I. A. C.; Matias, P. M., Redox State-Dependent Changes in the Crystal Structure of [NiFeSe] Hydrogenase from Desulfovibrio Vulgaris Hildenborough. Int. J. Hydrogen Energ. 2013, 38, 86648682. 